\title{
Outcomes of a postoperative perfluorocarbon liquid tamponade for complex retinal detachments: 12 years of experience in southern Thailand
}

\author{
Patama Bhurayanontachai ${ }^{*}$ (D) and Usanee Seepongphun
}

\begin{abstract}
Background: The study evaluates both functional and anatomical outcomes of retinal detachment (RD) repair by vitrectomy and perfluorocarbon liquid (PFCL) tamponade.

Methods: A retrospective chart review of patients who underwent vitrectomy using PFCL tamponade for RD repair from causes such as giant tear, chronic $\mathrm{RD}$, or $\mathrm{RD}$ with previously failed surgery.

Results: This study included 122 eyes from 121 patients. One-hundred fourteen eyes (93.5\%) had baseline vision worse than 20/200. The median duration of intraocular PFCL retainment was 14 days before gas or silicone oil replacement. The retinal reattachment rate was $80.3 \%$. At 1 year, the retention probability of retinal reattachment was 0.84 (95\% confidence interval, 0.77-0.91). Although visual improvement was found in $45.9 \%$ of patients, the median of final vision was not different between baseline and the last visit.
\end{abstract}

Conclusion: The rate of retinal reattachment operated with a short- to medium-term PFCL tamponade achieved a high satisfaction rate. However, postoperative hypotony was a predictor for unfavorable visual and anatomical outcomes.

Keywords: Giant tear, Perfluorocarbon liquid, Retinal detachment, Tamponade, Vitrectomy

\section{Background}

Perfluorocarbon liquid (PFCL) is a synthetic, fluorinated, carbon-containing compound. It is clear, colorless, odorless, and heavier than water. The PFCL does not affect the intraoperative view. The physical properties of PFCL make it an ideal tool for flattening the retina during vitreoretinal surgery for many types of pathologies, such as retinal detachment (RD) with severe proliferative vitreoretinopathy (PVR) [1-4], giant retinal tear [5-10], and pediatric RD [11]. Patients with chronic RD or those who underwent previously failed surgery are frequently accompanied by severe PVR, which sometimes produces

\footnotetext{
* Correspondence: patama103@yahoo.com.au

Department of Ophthalmology, Faculty of Medicine, Prince of Songkla University, 15 Karnjanawanich Road, Hat Yai, Songkhla 90110, Thailand
}

severe peripheral retinal contraction and shortening and may require a retinectomy. During injection, the high specificity gravity of PFCL allows the detached retina to be smoothly flattened from the posterior pole and displaces unwanted subretinal fluid anteriorly passing through the presenting retinal breaks or peripheral retinectomy. In contrast, an air-fluid exchange flattens the retina from the periphery and pushes subretinal fluid toward the posterior pole; therefore, a retinotomy is required. Using PFCL can also be an alternative or adjunctive to the standard scleral buckling procedure.

A large multicenter study reported results of intraoperative PFCL-assisted vitrectomy for complex RD with PVR [2]. Other case series have reported results of primary vitrectomy with a short-term postoperative PFCL

(c) The Author(s). 2020 Open Access This article is licensed under a Creative Commons Attribution 4.0 International License, which permits use, sharing, adaptation, distribution and reproduction in any medium or format, as long as you give appropriate credit to the original author(s) and the source, provide a link to the Creative Commons licence, and indicate if changes were made. The images or other third party material in this article are included in the article's Creative Commons licence, unless indicated otherwise in a credit line to the material. If material is not included in the article's Creative Commons licence and your intended use is not permitted by statutory regulation or exceeds the permitted use, you will need to obtain permission directly from the copyright holder. To view a copy of this licence, visit http://creativecommons.org/licenses/by/4.0/. The Creative Commons Public Domain Dedication waiver (http://creativecommons.org/publicdomain/zero/1.0/) applies to the data made available in this article, unless otherwise stated in a credit line to the data. 
tamponade [3-8]. A few studies have reported results of reoperation or rescued vitrectomy with a medium- and long-term PFCL tamponade in complex RD [12-15]. However, studies of a short- to medium-term PFCL use in an Asian population are only few. In the literature, complications after PFCL tamponade included subretinal PFCL, PFCL-related intraocular inflammation, elevated intraocular pressure (IOP), and epiretinal membrane (ERM) $[8,12,13,15]$.

We conducted a retrospective study of patients who underwent vitreoretinal surgeries with a short- to medium-term PFCL tamponade. This study primarily aims to demonstrate both anatomical and functional results after PFCL placement and removal. The secondary aim was to evaluate factors that affect the outcomes.

\section{Methods}

\section{Data collection}

This retrospective study was approved by the Ethics Committee of the Faculty of Medicine, Prince of Songkla University, Songkhla, Thailand (REC number 58-36402-3). The study included patients with RD who underwent pars plana vitrectomy (PPV) using postoperative PFCL tamponade (with or without scleral buckling procedure) in the tertiary referral university hospital. Data collection was performed using the hospital's electronic database to identify patients who had RD and were treated by standard three-port PPV. The search terms used were the following International Statistical Classification of Diseases-10 and International Statistical Classification of Diseases-9-Clinical Modification codes: (1) H33.0 RD with retinal break, (2) H33.4 Traction detachment of retina, (3) H33.5 Other RDs, and (4) 14.74 Other mechanical vitrectomy by posterior approach.

Eligible patients were determined by manual search. The inclusion criteria included rhegmatogenous RD (RRD) from any cause, tractional RD (TRD), and any RRD or TRD having a previously failed treatment. The exclusion criteria were any concomitant ocular diseases, such as macular choroidal neovascularization, dense cataract, advanced or uncontrolled ocular disease (e.g., glaucoma, uveitis, uncontrolled systemic disease), pregnancy, or loss of critical data records.

The patients received 20- or 23-gauged PPV with PFCL (Perfluoron; Alcon Laboratories, Inc., Fort Worth, TX) tamponade by any of three vitreoretinal surgeons in our unit. The surgical techniques of all surgeons were performed in a similar way. A core vitrectomy was done, followed by posterior vitreous detachment induction and peripheral vitreous trimming. As much PVR as possible was removed before flattening the retina by PFCL. All patients were instructed to limit activities and lie in bed in a supine position during the postoperative period in the ward. Patients were allowed to ambulate in upright position only for meals and toileting. After 1 to 2 weeks, either perfluoropropane gas (Ispan $\mathrm{C}_{3} \mathrm{~F}_{8}$; Alcon Laboratories, Inc.) or silicone oil (Oxane 5700; Bausch and Lomb, Inc., Rochester, NY) tamponade was chosen for replacing PFCL in the second operation. Patients who required additional RD repair by reinfusion of PFCL were also excluded from the study. Any further operations to fix the residual $\mathrm{RD}$, as well as cataract surgery, to achieve patient's maximal visual potential were allowed.

\section{Data management}

All eyes underwent at least two operations: PFCL placement and PFCL removal. The date of surgery with PFCL placement was defined as the starting date of the study. Data were recorded at 1 week, 1 month, 3 months, and 6 months after PFCL removal, as well as at the last visit. These included best-corrected visual acuity (BCVA), postoperative retinal status, and postoperative complications.

The primary outcome was reattachment of the retina (anatomical outcome). The secondary outcomes were vision improvement (functional outcome) and complications during the follow-up period. Vision improvement was determined by an increase of at least one line of BCVA by Early Treatment Diabetic Retinopathy Study chart or a one-step gain of nonnumerical vision test (e.g., hand motion improved to counting of fingers) at the last visit compared with the baseline BCVA. The final visual outcome was then classified into two groups: "better or improved VA" and "stable or worsened VA". A logarithm of the minimum angle of resolution (logMAR) VA was also used for vision calculation and comparison. All defined complications were elevated IOP greater than $25 \mathrm{mmHg}$, hypotony (IOP, $<5 \mathrm{mmHg}$ ), cataract progression, optic disc atrophy, ERM, corneal decompensation or edema, and retained intraocular PFCL bubble.

\section{Statistical analysis}

Baseline characteristics and important variables were analyzed in an R program version 3.4.0 (The R Group, Vienna, Austria) with Epicalc software (Brixton Health, www.brixtonhealth.com). The continuous variables were described as mean \pm standard deviation (SD) or as median with interquartile range (IQR), depending on data distribution. The relationships between the status of either reattachment or final VA change were evaluated by Student's $t$ test or the Wilcoxon rank-sum test for continuous data and by chisquare test or Fisher's exact test for categorical data. The recurrence time of RD after PFCL removal was used to plot a Kaplan-Meier survival graph. To identify a correlation of variables to the final outcomes, significant variables in a univariate analysis were introduced into a multivariate analysis. A logistic regression was applied to predict factors on retinal reattachment and final visual outcome. A result was considered statistically significant when there was a $P$ value less than 0.05 . 
Table 1 General characteristics of patients

\begin{tabular}{|c|c|c|}
\hline Characteristics & $\boldsymbol{N}=122$ & $(\%)$ \\
\hline \multicolumn{3}{|l|}{ Age $(y)$} \\
\hline Mean & $42( \pm 18.5)$ & \\
\hline Median & $43.5(6-83)$ & \\
\hline \multicolumn{3}{|l|}{ Sex } \\
\hline Male & 87 & 71.3 \\
\hline Female & 35 & 28.7 \\
\hline \multicolumn{3}{|l|}{ Laterality } \\
\hline Right & 66 & 54.1 \\
\hline Left & 56 & 45.9 \\
\hline \multicolumn{3}{|l|}{ Preoperative BCVA } \\
\hline$>20 / 70$ & 2 & 1.6 \\
\hline 20/70-20/200 & 6 & 4.9 \\
\hline$<20 / 200$ & 114 & 93.5 \\
\hline \multicolumn{3}{|l|}{ Preoperative logMAR BCVA } \\
\hline Mean & $1.8( \pm 0.4)$ & \\
\hline Median & $2(0.4-2.3)$ & \\
\hline \multicolumn{3}{|l|}{ Lens status } \\
\hline Phakic & 75 & 61.5 \\
\hline Pseudophakic & 33 & 27.0 \\
\hline Aphakic & 13 & 10.7 \\
\hline Unknown & 1 & 0.8 \\
\hline Average time of symptom-to-PFCL placement (d) & $125( \pm 156.1)$ & \\
\hline \multicolumn{3}{|l|}{ Duration of PFCL placement (d) } \\
\hline Mean & $12.4( \pm 2.8)$ & \\
\hline Median & $14(5-21)$ & \\
\hline \multicolumn{3}{|l|}{ Cause: PFCL placement as a primary surgery $(n=80)$} \\
\hline RRD-chronic & 32 & 26.2 \\
\hline RRD-giant tear & 27 & 22.1 \\
\hline TRD & 11 & 9.0 \\
\hline Trauma & 11 & 9.0 \\
\hline \multicolumn{3}{|l|}{ PFCL placement as a rescue surgery $(n=42)$} \\
\hline RRD-failed repair & 30 & 24.6 \\
\hline RRD-giant tear & 5 & 4.1 \\
\hline TRD & 2 & 1.6 \\
\hline Trauma & 4 & 3.3 \\
\hline \multicolumn{3}{|l|}{ Reattachment: } \\
\hline Yes & 98 & 80.3 \\
\hline No & 22 & 18.0 \\
\hline Cannot be evaluated & 2 & 1.6 \\
\hline \multicolumn{3}{|l|}{ Interval before failed reattachment, $n=22$ (wk) } \\
\hline Mean & $40.8( \pm 53.1)$ & \\
\hline Median & $30.2(1.7-243.1)$ & \\
\hline \multicolumn{3}{|l|}{ Follow-up time (wk) } \\
\hline Mean & $101.6( \pm 101.0)$ & \\
\hline
\end{tabular}


Table 1 General characteristics of patients (Continued)

\begin{tabular}{ll}
\hline Characteristics & $\boldsymbol{N}=122$ \\
\hline Median & $67.6(2.7-461.1)$ \\
Final logMAR VA & \\
Mean & $1.6( \pm 0.7)$ \\
Median & $2(0.1-3.0)$ \\
\hline
\end{tabular}

BCVA best-corrected visual acuity; logMAR logarithm of the minimum angle of resolution; $P F C L$ perfluorocarbon liquid; $R R D$ rhegmatogenous retinal detachment; TRD tractional retinal detachment; VA visual acuity

\section{Results}

\section{General characteristics}

Table 1 summarizes the general patient characteristics. The raw data used to support the findings of this study are available from the corresponding author upon request. The study included 122 eyes from 121 patients. The BCVA ranged from 20/50 to perception of light. Most of the eyes $(63.1 \%)$ began with hand motion. For 76 eyes in which RD was not chronic and the onset of visual symptoms could be obtained, the mean duration from the onset to the operation with PFCL placement was $125.8 \pm 155$ days. The mean interval between the latest vitrectomy and the starting date of the study was 173.6 \pm 395.2 days (range, 3-2527 days). Four eyes with giant tear and five eyes with chronic RRD were myopic. Cytomegalovirus retinitis accounted for three cases of chronic RRD. Trauma cases included penetrating ocular injuries, traumatic RRD with vitreous hemorrhage, and intraocular foreign bodies. Previous vitreous surgeries in 42 eyes (34.4\%) included simple PPV without vitreous substitution, PPV with gas or silicone oil tamponade, PPV for intraocular foreign body removal, and anterior vitrectomy.

In 30 eyes with previously failed RD repair, $64.5 \%$ had received silicone oil endotamponade, and the rest had received gas endotamponade before PFCL placement. A retinectomy was performed in $36.6 \%$ of these eyes. A retinectomy with PFCL placement was also performed in 31 (53.1\%) eyes with chronic RD and 13 (76.9\%) eyes with severe TRD.

After the operation with PFCL placement, 97.5\% of the retinas were reattached at the time of PFCL removal. When PFCL was removed, 101 eyes (82.8\%) were replaced by silicone oil and 21 eyes (17.2\%) were replaced by gas. Of the 80 eyes (65.6\%), 38 had additional operation for silicone oil removal, 33 had combined surgery for cataract extraction and silicone oil removal, 4 required additional vitrectomy for residual RD repair, 3 had cataract extraction only, 1 had an ERM peeling, and

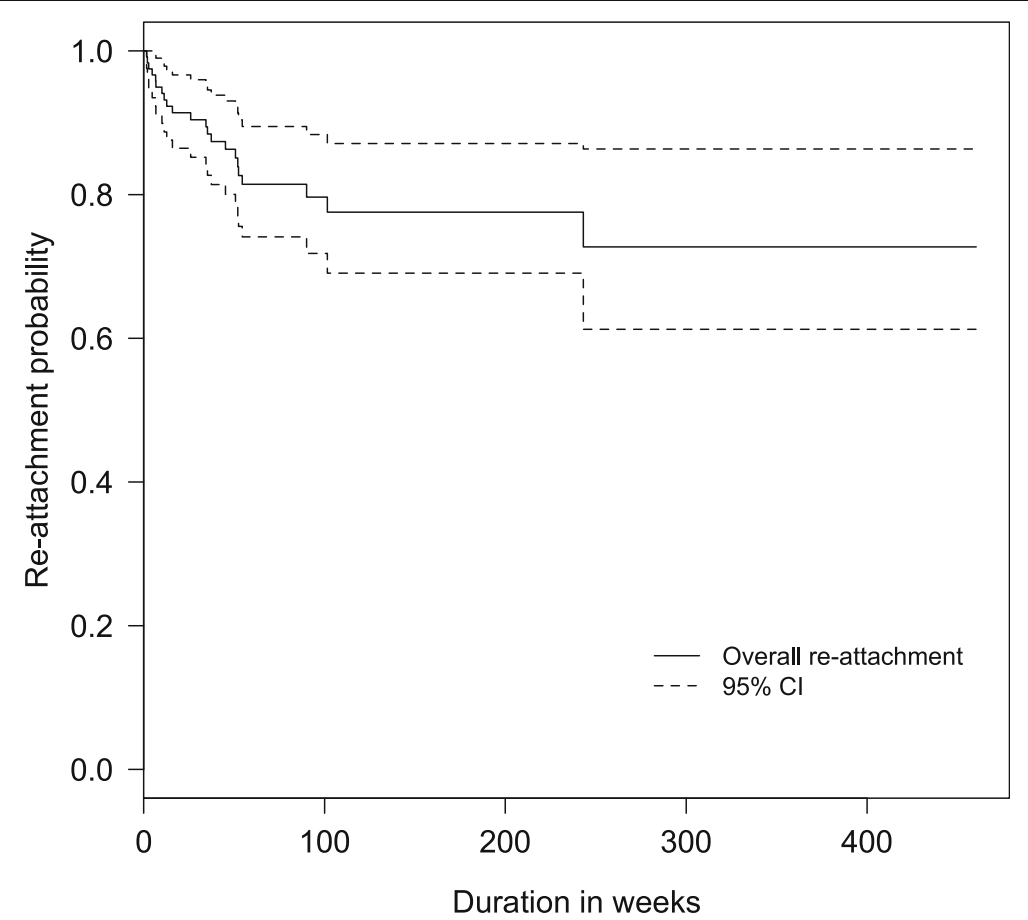

Fig. 1 Kaplan-Meier estimation of retention of retinal re-attachment by time 
Table 2 Postoperative best-corrected visual acuity

\begin{tabular}{|c|c|c|c|c|c|}
\hline Visual acuity at: & 1 week & 1 month & 3 month & 6 month & Last visit \\
\hline Number of eyes (n) & 119 & 120 & 115 & 110 & 122 \\
\hline$>20 / 70$ & $1(0.8 \%)$ & $3(2.5 \%)$ & $5(4.3 \%)$ & $3(2.7 \%)$ & $12(9.8 \%)$ \\
\hline 20/70-20/200 & $10(8.4 \%)$ & $23(19.2 \%)$ & $25(21.7 \%)$ & $22(20.0 \%)$ & $25(20.5 \%$ \\
\hline$<20 / 200-P L$ & $108(90.8 \%)$ & $94(78.3 \%)$ & $85(73.9 \%)$ & $85(77.3 \%)$ & $76(62.3 \%$ \\
\hline No PL & 0 & 0 & 0 & 0 & $9(7.4 \%)$ \\
\hline
\end{tabular}

1 had partial silicone oil release to reduce elevated postoperative IOP.

Of the 11 eyes (9\%), 3 had cataract surgery or secondary intraocular lens insertion, 3 had a recurrent detachment repair with silicone oil tamponade, 2 had combined surgery for cataract extraction and silicone oil removal, 1 had four operations for silicone oil removal, 1 had an intravitreal antibiotic injection for suspected endophthalmitis, and 1 had an evisceration for phthisis bulbus.

Three eyes $(2.5 \%)$ had fifth operations, one each for silicone oil removal, intraocular lens reposition, and band keratopathy removal. Only one patient, who had undergone a band keratopathy removal, underwent a sixth operation for silicone oil removal. A residual PFCL droplet in the anterior chamber or in the vitreous cavity was noted in six eyes (4.9\%). However, none of them were confronted with subretinal PFCL.

Retinal reattachment was achieved in all cases during PFCL retention in the vitreous cavity. The reattachment rate at the last visit was $80.3 \%$. Figure 1 demonstrates that the recurrent RD after PFCL removal was more likely to occur in the early phase. At 1 year, the probability of

Table 3 Relationship between preoperative factors, retinal reattachment, and the final VA status

\begin{tabular}{|c|c|c|c|c|c|c|}
\hline & \multicolumn{2}{|l|}{ Reattachment } & \multirow{2}{*}{$\begin{array}{l}P \\
\text { value }\end{array}$} & \multicolumn{2}{|l|}{ Final VA Status } & \multirow{2}{*}{$\begin{array}{l}P \\
\text { value }\end{array}$} \\
\hline & $\begin{array}{l}\text { No } \\
(n=22)\end{array}$ & $\begin{array}{l}\text { Yes } \\
(n=98)\end{array}$ & & $\begin{array}{l}\text { Better } \\
(n=56)\end{array}$ & Stable or worse $(n=66)$ & \\
\hline Mean age (SD) & $34.3( \pm 17.6)$ & $43.8( \pm 18.1)$ & $0.027^{*}$ & $41.9( \pm 16.8)$ & $42.1( \pm 19.9)$ & 0.953 \\
\hline \multicolumn{7}{|l|}{ Sex } \\
\hline Female & $6(27.3)$ & $29(29.6)$ & \multirow[t]{2}{*}{1.000} & $14(25)$ & $21(31.8)$ & \multirow[t]{2}{*}{0.529} \\
\hline Male & $16(72.7)$ & $69(70.4)$ & & $42(75)$ & $45(68.2)$ & \\
\hline \multicolumn{7}{|l|}{ Laterality } \\
\hline Left eye & $16(72.7)$ & $40(40.8)$ & \multirow[t]{2}{*}{$0.013^{*}$} & $24(42.9)$ & $32(48.5)$ & \multirow[t]{2}{*}{0.660} \\
\hline Right eye & $6(27.3)$ & $58(59.2)$ & & $32(57.1)$ & $34(51.5)$ & \\
\hline Median logMAR VA (IQR) & $2(2-2)$ & $2(1.7-2)$ & 0.569 & $2(1.6-2)$ & $2(2-2)$ & 0.134 \\
\hline \multicolumn{7}{|l|}{ Lens } \\
\hline Aphakic & $2(9.1)$ & $11(11.3)$ & \multirow[t]{3}{*}{0.101} & $3(5.5)$ & $10(15.2)$ & \multirow[t]{3}{*}{0.214} \\
\hline Pseudophakic & $2(9.1)$ & $29(29.9)$ & & $15(27.3)$ & $18(27.3)$ & \\
\hline Phakic & $18(81.8)$ & $57(58.8)$ & & $37(67.3)$ & $38(57.6)$ & \\
\hline \multicolumn{7}{|l|}{ Cause } \\
\hline Chronic RRD & $6(27.3)$ & $26(26.5)$ & \multirow[t]{5}{*}{0.970} & $12(21.4)$ & $20(30.3)$ & \multirow[t]{5}{*}{$0.001^{*}$} \\
\hline Giant tear & $6(27.3)$ & $26(26.5)$ & & $24(42.9)$ & $8(12.1)$ & \\
\hline Trauma & $3(13.6)$ & $12(12.2)$ & & $5(8.9)$ & $10(15.2)$ & \\
\hline Previously failed RD repair & $4(18.2)$ & $24(24.5)$ & & $13(23.2)$ & $17(25.8)$ & \\
\hline TRD & $3(13.6)$ & $10(10.2)$ & & $2(3.6)$ & $11(16.7)$ & \\
\hline \multicolumn{7}{|l|}{ Previous vitrectomy } \\
\hline No & $15(68.2)$ & $65(66.3)$ & \multirow[t]{2}{*}{1.000} & 39 (69.6) & $41(62.1)$ & \multirow[t]{2}{*}{0.496} \\
\hline Yes & $7(31.8)$ & $33(33.7)$ & & $17(30.4)$ & $25(37.9)$ & \\
\hline Median time of symptom-to-PFCL placement (IQR) & $64(20-117)$ & $55(17-165)$ & 0.804 & $45(15-128.5)$ & $82.5(35.2-258.8)$ & 0.098 \\
\hline Median duration of PFCL placement (IQR) & $13.5(10.2-14)$ & $14(11-14)$ & 0.817 & $12(10-14)$ & $14(11-14)$ & 0.221 \\
\hline
\end{tabular}


retention of retinal reattachment was 0.84 (95\% confidence interval, 0.77-0.91). By the end of the eighth year, nearly three-quarters of patients who returned for followup still had their operated retinas attached.

Table 2 demonstrates groups of postoperative BCVA at different time points during the follow-up period. The vision of most eyes tended to improve over time. The final BCVA improved from baseline in 56 eyes (45.9\%), remained stable in 46 eyes (37.7\%), and worsened in 20 eyes (16.4\%).

The most common complication was an immediate postoperative IOP elevation (51.2\%), which usually occurred the next day after PFCL placement. IOP elevation and hypotony occurring after PFCL removal was found in 25.4 and $23 \%$ of eyes, respectively. Optic nerve atrophy and cataract progression were equally found in $22.1 \%$ of eyes. ERM occurred in $13.1 \%$ of eyes. A case of suspected late postoperative endophthalmitis, occurring at 5 years after the patient's third operation of combined phacoemulsification and silicone oil removal, was successfully treated with a single injection of intravitreal antibiotics.

The univariate analyses of the effect of pre- and postoperative variables on retinal reattachment and visual outcome are demonstrated in Tables 3 and 4. Although male sex was predominant in the study, sex had no effect on either anatomical or visual outcome $(P=0.828$ and 0.405 , respectively).

Table 5 summarizes the results of multivariate analyses of characteristics regarding anatomical and functional successes. The significant predicting factors for retinal reattachment were right eye, lens status, and the absence of postoperative hypotony. Pseudophakic eyes appeared to have a better anatomical outcome than aphakic and phakic eyes. The significant predicting factors for better final BCVA were RD caused by giant tear and the absence of postoperative hypotony.

\section{Discussion}

Our study included 122 eyes from 121 patients with varied retinal pathologies. Difficult cases such as chronic RRD with PVR and previously failed surgery for retinal attachment comprised more than half of the patients included. The duration from the patient's symptoms to the starting date of this study was $125 \pm 156.1$ days. Therefore, the chronicity of the RD would be at least 4 or more months on average. The longer the duration of

Table 4 Relationship between immediate- and medium-term postoperative conditions, final retinal reattachment, and VA status

\begin{tabular}{|c|c|c|c|c|c|c|}
\hline & \multicolumn{2}{|c|}{ Reattachment } & \multirow{2}{*}{$\begin{array}{l}P \\
\text { value }\end{array}$} & \multicolumn{2}{|c|}{ Final VA Status } & \multirow[t]{2}{*}{$P$ value } \\
\hline & $\begin{array}{l}\text { No } \\
(n=22)\end{array}$ & $\begin{array}{l}\text { Yes } \\
(n=98)\end{array}$ & & $\begin{array}{l}\text { Better } \\
(n=56)\end{array}$ & Stable or worse $(n=66)$ & \\
\hline \multicolumn{7}{|c|}{ Elevated IOP during PFCL placement } \\
\hline No & $13(59.1)$ & $46(46.9)$ & 0.427 & $24(42.9)$ & $35(53.8)$ & 0.306 \\
\hline Yes & $9(40.9)$ & $52(53.1)$ & & $32(57.1)$ & $30(46.2)$ & \\
\hline \multicolumn{7}{|c|}{ Elevated IOP after PFCL removal } \\
\hline No & $17(77.3)$ & $72(73.5)$ & 0.921 & 39 (69.6) & $52(78.8)$ & 0.343 \\
\hline Yes & $5(22.7)$ & $26(26.5)$ & & $17(30.4)$ & $14(21.2)$ & \\
\hline \multicolumn{7}{|c|}{ Hypotony } \\
\hline No & $12(54.5)$ & $81(82.7)$ & $0.009^{*}$ & $52(92.9)$ & $42(63.6)$ & $<0.001^{*}$ \\
\hline Yes & $10(45.5)$ & $17(17.3)$ & & $4(7.1)$ & $24(36.4)$ & \\
\hline \multicolumn{7}{|c|}{ Optic disc atrophy } \\
\hline No & $18(81.8)$ & $75(76.5)$ & 0.779 & $50(89.3)$ & $45(68.2)$ & $0.01^{*}$ \\
\hline Yes & $4(18.2)$ & $23(23.5)$ & & $6(10.7)$ & $21(31.8)$ & \\
\hline \multicolumn{7}{|c|}{ Cataract progression } \\
\hline No & $17(77.3)$ & $76(77.6)$ & 1.000 & $44(78.6)$ & $51(77.3)$ & 1.000 \\
\hline Yes & $5(22.7)$ & $22(22.4)$ & & $12(21.4)$ & $15(22.7)$ & \\
\hline \multicolumn{7}{|c|}{ Corneal decompensation } \\
\hline No & $16(72.7)$ & $84(85.7)$ & 0.201 & $52(92.9)$ & $50(75.8)$ & $0.022^{*}$ \\
\hline Yes & $6(27.3)$ & 14 (14.3) & & $4(7.1)$ & $16(24.2)$ & \\
\hline \multicolumn{7}{|l|}{ ERM } \\
\hline No & $20(90.9)$ & $84(85.7)$ & 0.733 & $48(85.7)$ & $58(87.9)$ & 0.933 \\
\hline Yes & $2(9.1)$ & $14(14.3)$ & & $8(14.3)$ & $8(12.1)$ & \\
\hline
\end{tabular}

ERM epiretinal membrane; IOP intraocular pressure; PFCL perfluorocarbon liquid; $V A$ visual acuity 
Table 5 Logistic regression of predicting factors on retinal reattachment and final visual outcome

\begin{tabular}{|c|c|c|c|}
\hline \multicolumn{4}{|l|}{ Predicting reattachment } \\
\hline & Adjusted OR (95\% Cl) & $P$ value (Wald's test) & $P$ value (LR test) \\
\hline \multicolumn{4}{|l|}{ Laterality } \\
\hline Left eye & 1 & $0.013^{*}$ & $0.009^{*}$ \\
\hline Right eye & $4.2(1.35-13.01)$ & & \\
\hline \multicolumn{4}{|l|}{ Lens status } \\
\hline Aphakic & 1 & 0.440 & $0.041^{*}$ \\
\hline Pseudophakic & $2.53(0.24-26.75)$ & 0.274 & \\
\hline Phakic & $0.38(0.07-2.15)$ & & \\
\hline \multicolumn{4}{|l|}{ Hypotony } \\
\hline Yes & 1 & $0.005^{*}$ & $0.005^{*}$ \\
\hline No & $5.18(1.62-16.52)$ & & \\
\hline \multicolumn{4}{|l|}{ Predicting improved final BCVA } \\
\hline \multicolumn{4}{|l|}{ Cause } \\
\hline Trauma & 1 & 0.858 & $0.004^{*}$ \\
\hline Chronic RRD & $1.13(0.29-4.38)$ & $0.016^{*}$ & \\
\hline Giant tear RRD & $5.66(1.38-23.20)$ & 0.495 & \\
\hline Previously failed RD repair & $1.61(0.41-6.31)$ & 0.350 & \\
\hline TRD & $0.40(0.06-2.73)$ & & \\
\hline \multicolumn{4}{|l|}{ Hypotony } \\
\hline Yes & 1 & $0.002^{*}$ & $<0.001^{*}$ \\
\hline No & $6.83(2.07-22.52)$ & & \\
\hline
\end{tabular}

$\mathrm{RD}$, the higher the risk of surgical failure in these patients. Therefore, silicone oil was a preferred choice of vitreous substitution to hold the retina in place after the retina was successfully reattached by PFCL $(81.1 \%$, oil; $17.2 \%$, gas) and to lessen the risk of postoperative hypotony.

The result showed that a short- and medium-term PFCL retainment ( $\leq 20$ days) was safe enough for complex $\mathrm{RD}$ repair in real-life practice. The success rate of reattachment was $80.3 \%$ of eyes. The causes of RD had an effect on the final visual outcome, but not on the retinal reattachment rate. A TRD, which was mostly caused by proliferative diabetic retinopathy, had the worst visual prognosis. The eyes with giant tear achieved better final vision than eyes with RD from other causes. This may be because of the fact that $84.4 \%$ of eyes with giant tear underwent a PFCL-assisted surgery on the first attempt and PVR was not involved much in these surgeries. The success of using PFCL in eyes with chronic RD and with reoperation was compromised from the preoperative PVR. An interval from the onset of symptoms to the time of PFCL placement did not affect the reattachment rate.

The majority of patients started with baseline VA worse than 20/200. The visual level at the last visit had improved in $45.9 \%$ of eyes. Eyes with giant tear accounted for the highest percentage of postoperative vision improvement. Mean $\log$ MAR VA increased from $1.8 \pm 0.4$ at baseline to $1.6 \pm 0.7$ at the last visit. However, the median $\log$ MAR VA was not different between baseline (2, 0.4-2.3) and last visit (2, 0.1-3.0). Other studies have reported a visual improvement that varied from 56.8 to $60 \%[1,4]$.

The retinal reattachment rate with the use of PFCL in our study was comparable to the rate of $76-100 \%$ reported by other studies [2-13], even though postoperative visual improvement was not as good as the anatomical improvement.

Our results showed a high rate of early postoperative IOP elevation in the next day after PFCL placement, which could be controlled by medication in all patients. Other reports found a transient IOP elevation that varied from none to $35.9 \%$ at any time postoperatively [8, 13]. We also found that an IOP fluctuation was the main problem associated with either PFCL placement or PFCL removal. However, this did not affect the reattachment rate. Postoperative hypotony was noted to be a strong predictor for both anatomical and unfavorable visual outcomes.

Retinal toxicities and foreign body reaction from PFCL were occasionally reported $[15,16]$. There was no sign 
of retinal toxicity from the PFCL reported in our study. However, optic nerve atrophy was found in $22.1 \%$ of the overall cases in the late postoperative period, and this compromised a visual recovery in successful cases. Either using PFCL or repeated surgeries could account for late optic nerve atrophy.

There were some limitations in this study. First, our center is a tertiary referral hospital; therefore, selection bias might have occurred. Second, the study was conducted retrospectively. Third, a small number of patients with TRD made it difficult to strongly predict the final visual prognosis. Finally, some patients still had their eyes filled with silicone oil at the end of the data collection period; therefore, the recorded BCVA might not reflect their true, final visual outcomes.

\section{Conclusion}

Using short- to medium-term PFCL tamponade for complex RD was anatomically successful in $80.3 \%$ of patients in this study. At least one-line or one-level vision gain was achieved in $45.9 \%$ of eyes. Postoperative hypotony was a strong predictor for both anatomical and unfavorable visual outcomes.

\section{Abbreviations}

BCVA: Best-corrected visual acuity; ERM: Epiretinal membrane; IOP: Intraocular pressure; logMAR: logarithm of the minimum angle of resolution; PFCL: Perfluorocarbon liquid; PPV: Pars plana vitrectomy; PVR: Proliferative vitreoretinopathy; RD: Retinal detachment

\section{Acknowledgements}

The authors acknowledge Prof. Virasakdi Chongsuvivatwong, Ms. Jirawan Jayuphan and Ms. Parichart Damthongsuk for their help with this study.

\section{Authors' contributions}

PB was responsible for the conceptualization and methodology. PB and US collected and analyzed the data. US wrote the draft. PB wrote and substantively revised the manuscript. All authors have read and approved the manuscript.

\section{Funding}

Not applicable.

\section{Availability of data and materials}

The datasets used and/or analysed in the current study are available from the corresponding author on reasonable request.

\section{Ethics approval and consent to participate}

This study was approved by the Ethics Committee of the Faculty of Medicine, Prince of Songkla University, Songkhla, Thailand (REC number 58364-02-3). Consent to participate was not applicable.

\section{Consent for publication}

Not applicable.

\section{Competing interests}

The authors declare no conflicts of interest.

Received: 21 February 2020 Accepted: 5 August 2020

Published online: 01 September 2020

\section{References}

1. Scott IU, Flynn HW Jr, Murray TG, Feuer WJ. Perfluoron study group. Outcomes of surgery for retinal detachment associated with proliferative vitreoretinopathy using perfluoro-n-octane: a multicenter study. Am J Ophthalmol. 2003;136:454-63.

2. Sigler EJ, Randolph JC, Calzada JI, Charles S. 25-gauge pars plana vitrectomy with medium-term postoperative perfluoro-N-octane tamponade for inferior retinal detachment. OSLI Retina. 2013;44:34-40.

3. Kirchhof B, Wong D, Van Meurs J, Hilgers RD, Macek M, Lois N, Schrage NF. Use of perfluorohexyloctane as a long-term internal tamponade agent in complicated retinal detachment surgery. Am J Ophthalmol. 2002;133:95101.

4. Sigler EJ, Randolph JC, Calzada Jl, Charles S. Pars plana vitrectomy with medium-term postoperative perfluoro-N-octane for recurrent inferior retinal detachment complicated by advanced proliferative vitreoretinopathy. Retina. 2013:33:791-7.

5. Mikhail MA, Mangioris G, Best RM, McGimpsey S, Chan WC. Management of giant retinal tears with vitrectomy and perfluorocarbon liquid postoperatively as a short-term tamponade. Eye. 2017;31:1290-5.

6. Eiger-Moscovich M, Gershoni A, Axer-Siegel R, Weinberger D, Ehrlich R. Short-term vitreoretinal tamponade with heavy liquid following surgery for giant retinal tear. Curr Eye Res. 2017;42:1074-8.

7. Zhang Z, Wei $Y$, Jiang X, Zhang S. Surgical outcomes of 27-gauge pars plana vitrectomy with short-term postoperative tamponade of perfluorocarbon liquid for repair of giant retinal tears. Int Ophthalmol. 2018; 38:1505-13

8. Randolph JC, Diaz RI, Sigler EJ, Calzada JI, Charles S. 25-gauge pars plana vitrectomy with medium-term postoperative perfluoro-n-octane for the repair of giant retinal tears. Graefes Arch Clin Exp Ophthalmol. 2016;254 253-7.

9. Sirimaharaj M, Balachandran C, Chan WC, Hunyor AP, Chang AA, Roberts JG, Hunyo AB, Playfair TJ. Vitrectomy with short term postoperative tamponade using perfluorocarbon liquid for giant retinal tears. Br J Ophthalmol. 2005; 89:1176-9.

10. Rofail M, Lee LR. Perfluoro-n-octane as a postoperative vitreoretinal tamponade in the management of giant retinal tears. Retina. 2005;25:897901.

11. Reza AT. Postoperative perfluro-N-octane tamponade for complex retinal detachment surgery. Bangladesh Med Res Counc Bull. 2014;40:63-9.

12. Drury B, Bourke RD. Short-term intraocular tamponade with perfluorocarbon heavy liquid. Br J Ophthalmol. 2011;95:694-8.

13. Rush R, Sheth S, Surka S, Ho I, Roberts JG. Postoperative perfluoro-N-octane tamponade for primary retinal detachment repair. Retina. 2012;32:1114-20.

14. Méndez-Martínez S, Calvo P, Rodriguez-Marco NA, Faus F, Abecia E, Pablo L. Blindness related to presumed retinal toxicity after using perfluorocarbon liquid during vitreoretinal surgery. Retina. 2018;38:1856-64.

15. Yu Q, Liu K, Su L, Xia X, Xu X. Perfluorocarbon liquid: its application in vitreoretinal surgery and related ocular inflammation. Biomed Res Int. 2014; 2014:250323. https://doi.org/10.1155/2014/250323.

16. Inoue M, Iriyama A, Kadonosono K, Tamaki Y, Yanagi Y. Effects of perfluorocarbon liquids and silicone oil on human retinal pigment epithelial cells and retinal ganglion cells. Retina. 2009;29:677-81.

\section{Publisher's Note}

Springer Nature remains neutral with regard to jurisdictional claims in published maps and institutional affiliations.

Ready to submit your research? Choose BMC and benefit from:

- fast, convenient online submission

- thorough peer review by experienced researchers in your field

- rapid publication on acceptance

- support for research data, including large and complex data types

- gold Open Access which fosters wider collaboration and increased citations

- maximum visibility for your research: over $100 \mathrm{M}$ website views per year

At BMC, research is always in progress.

Learn more biomedcentral.com/submissions 